\title{
Incremental distinguishability of subject and object
}

\author{
Helen de Hoop \& Monique Lamers ${ }^{1}$
}

Radboud University Nijmegen

The subject and the object in a transitive clause should be distinguishable. We discuss five different ways in which distinguishability can be obtained: (i) case morphology, (ii) agreement, (iii) selectional criteria of the verb, (iv) word order, and (v) prominence, in particular animacy. We argue that these different sources of information can be viewed as violable and potentially conflicting constraints that play an important role in the incremental process of interpretation. We propose a new model of incremental optimization of interpretation and argue that we can thus account for the findings of several on-line studies in which distinguishability was manipulated.

\section{Introduction}

In 1981 a paper appeared by the Dutch linguist Frans Zwarts, entitled "Negatief polaire uitdrukkingen 1” (“Negative Polarity Items - part 1”). This title triggered the expectation among linguists in the Netherlands that once part 2 on negative polarity items would appear. So far this has not happened.

To call something part 1 triggers the expectation that there is or will be a part 2 as well. Maybe this expectation is even stronger if one encounters something that is called part 2: there has to be a part 1 then. Similarly, if one encounters an accusatively marked direct object in German (a part 2), the expectation is triggered that there must be a subject as well (a part $1)$.

(1) Den Zaun habe ich zerbrochen.

[the fence $]_{\text {ACC }}$ have $\mathrm{I}_{\mathrm{NOM}}$ broken

"I broke the fence."

\footnotetext{
${ }^{1}$ We greatly benefited from discussions with Ina Bornkessel and Matthias Schlesewsky about the matters discussed in the present paper. Furthermore, we thank two anonymous reviewers, the editors of this volume, as well as Gerlof Bouma, Petra Hendriks, Irene Krämer, Yukiko Morimoto, Henriëtte de Swart, and Joost Zwarts for helpful comments. The Netherlands Organisation of Scientific Research (NWO) is gratefully acknowledged for financial support (PIONIER project “Case cross-linguistically”, NWO Cognition project “Conflicts in Interpretation”, NWO-DFG project “Incremental interpretation of case and prominence”).
} 
Within the domain of language comprehension, it is well established that syntactic dependencies give rise to predictive parsing (Gibson, 1998). For example, the processing of an unambiguously identifiable object will give rise to the prediction of a subject.

In languages that have ergative case marking, this case marking can be conceived of as calling this noun phrase part 1, which gives rise to the expectation that there will be a part 2 . Note that with respect to subject and object marking, it usually appears to be sufficient to mark just one of the two arguments of a two-place predicate (either accusative case on the direct object, or ergative case on the subject), the other one can stay unmarked. That is, nominative and absolutive case forms (in nominative-accusative and ergative-absolutive languages respectively) are often the forms which lack morphological case-marking. An example from Yup'ik is given below.

(2) Angutem tangrr-aa arnaq.

$\operatorname{man}_{\text {ERG }}$ sees woman $\mathrm{ABS}$

"The man sees the woman."

In other words, one function of accusative case and ergative case may be viewed as similar, namely as distinguishing between the two arguments of a transitive (two-place) relation.

Accordingly, whenever there is only one argument, i.e., in the case of a one-place predicate, this argument does not have to be case-marked at all from a functional point of view. The most unmarked and often morphologically null case is the nominative case in nominative-accusative case systems and the absolutive case in ergative-absolutive case systems. The morphologically unmarked case is sometimes referred to as the obligatory case because it is usually present in both transitive and intransitive sentences (cf. Bobaljik 1993). That is, nominative/absolutive case captures the unmarked 'other part' of a transitive construction as well as the one and only argument of an intransitive construction.

(3) Der Mann tanzt.

the $\mathrm{NOM}_{\mathrm{M}}$ man dances

“The man dances."

(4) Arnaq yruar-tuq.

woman $_{\mathrm{ABS}}$ dances

“The woman dances.” 
In other words, if there is only one argument (of a one-place predicate) it does not have to be (case-) marked to distinguish it from another argument. Similarly indeed, it does not make sense to call a paper on negative polarity items part 1 if there is no and will not be a part 2 . In languages that do have morphological case, the case properties of arguments reflect not only the grammatical function (part 1 or part 2), but also to a certain degree their thematic and other semantic properties. The choice for a certain case may, for instance, depend on temporal or aspectual properties of the predicate or on individual properties of the relevant noun phrase arguments, such as animacy and specificity (cf. De Swart, this volume). Although this can often be related to the distinguishing function of case marking, i.e., to avoid (potential) ambiguity with respect to the argument structure of a transitive predicate, other cases of potential ambiguity may also trigger case-marking.

\section{Five ways to distinguish between subjects and objects}

In the previous section we discussed what might be called a general strategy to avoid ambiguity with regard to the arguments in a two-place transitive relation. This leads us to propose the following universal constraint:

\section{(5) DISTINGUISHABILITY}

The two arguments of a transitive relation should be distinguishable.

The principle of DisTINGUISHABILITY specifies that, in a transitive relation, the two arguments should be distinct from each other (variants of this constraint and elaborate discussions are found in recent work, e.g. Bornkessel 2002, Næss 2004, and De Swart 2003, this volume). For the sake of convenience, we will refer to the first argument of a transitive relation as the subject and to the second one as the object (yet, we are aware of the fact that subject and object are grammatical labels that do not always link straightforwardly to the argument structure of a transitive verb or do only partially so).

DisTINGUISHABILITY can be satisfied in many different ways of which we will briefly discuss five. One way of distinguishing the two arguments of a transitive relation is by the use of morphological marking, in particular case. As we have seen above, two arguments can 
already be distinguished when only one bears unambiguous morphological case marking, e.g., when the object bears accusative case.

Secondly, arguments may be distinguished on the basis of prominence in the sense that the subject is often more prominent (in the discourse) than the object. Prominence can be measured along different scales, such as animacy, specificity, or (pronominal) person (cf. a.o. Comrie 1989, Aissen 2003, Lee 2003). We take animacy to be one important factor on the basis of which the condition that the subject outranks the object on a relevant scale of discourse prominence may be fulfilled. Although it is not the only factor, we mostly limit ourselves in this article to cases in which the subject outranks the object on the scale of animacy, that is where the subject is animate while the object is inanimate. At some point, we will also see an example in which definiteness or specificity plays a similar role.

Thirdly, the use of word order may give us a clue as to which argument is the subject and which is the object in the transitive sentence, for example when the canonical word order is such that the subject precedes the object.

Fourthly, the verb itself may provide the necessary information in order to distinguish the two arguments. For example, please takes an experiencer (animate) object, while like takes an experiencer (animate) subject. Therefore, when there is an animate and an inanimate noun phrase available, it is clear which one has to be the subject and which one the object in the context of one of these verbs. The case of like with an animate subject and an inanimate object not only satisfies distinguishability on the basis of selection criteria of the verb, but this goes hand in hand with a satisfaction of distinguishability on the basis of prominence or animacy. By contrast, the case of please with an animate object and an inanimate subject satisfies distinguishability on the basis of selection criteria of the verb but at the same time it violates distinguishability on the basis of prominence or animacy, since the subject does not outrank the object on the animacy scale.

Last but not least, agreement with the verb may determine the subject in languages such as German and English, and both subject and object in languages with subject and object agreement.

Obviously, there may be other ways to distinguish between the two arguments of a transitive relation, such as prosody or surrounding context, but in this paper we will limit our discussion to the five factors mentioned above. 


\section{Conflicts among distinguishability constraints}

As outlined above, we conceive of DistinguishabiLiTy as a family of constraints that contribute to the distinguishability of the two arguments of a transitive relation on the basis of (i) morphological case marking; (ii) a difference in (discourse) prominence such that the subject outranks the object in prominence (e.g., animacy); (iii) word order such that the subject precedes the object in linear word order; (iv) selection criteria of the verb, when the verb selects an animate subject or an animate object; (v) agreement such that the verb agrees with the subject. We will refer to these constraints as CASE, PROMINENCE, PRECEDENCE, SELECTION, and AGREEMENT respectively. At this point, let us formulate these constraints in a precise way so that they can be evaluated for a given input, and let us determine the ranking of the constraints in German.

(6) DistingUISHABILITY constraints:

a. CASE: the subject is in the nominative case, the object is in the accusative case

b. AGREEMENT: the verb agrees with the subject

C. SELECTION: fit the selectional restrictions of the verb (animacy)

d. PRECEDENCE: the subject (linearly) precedes the object

e. PROMINENCE: the subject outranks the object in prominence (animacy)

As a first example of how the constraints are applied in the process of interpretation, consider the following German sentence.

(7) Ich habe den Zaun zerbrochen.

$\mathrm{I}_{\mathrm{NOM}}$ have [the fence $]_{\mathrm{ACC}}$ broken

"I broke the fence."

In (7) the two arguments of the transitive predicate can be distinguished on the basis of all of the DistinguishabiLiTY-constraints: (i) den Zaun must be the object because of the accusative case marking, while the subject is in the nominative; (ii) the finite verb agrees with the first person subject, while the object is third person; (iii) the transitive verb to break normally selects an animate agent subject; (iv) the arguments are in the canonical order, i.e., subject before object; and finally (v) the subject is animate while the object is inanimate. The 
conclusion must be that it will not be hard for a hearer to distinguish between the subject and the object in (7) on the basis of the five constraints discussed. This is illustrated with help of the following tableau:

(8) Optimal interpretation of sentence (7)

\begin{tabular}{|r|c:c|c|c|c|}
\hline Ich habe den Zaun zerbrochen & CASE & AGREEMENT & SELECTION & PRECEDENCE & PROMINENCE \\
\hline Subject-initial (SI) & & & & & \\
\hline Object-initial (OI) & $*$ & $*$ & $*$ & $*$ & $*$ \\
\hline
\end{tabular}

What we see very clearly in the tableau in (8) is that there is one interpretation which satisfies all five constraints. This optimal interpretation is the subject-initial interpretation, the one where ich ' $\mathrm{I}$ ' is the subject and den Zaun 'the fence' the object.

The ranking as indicated in the tableau above, where CASE and AgREEMENT are not ranked with respect to each other (as can be seen from the dotted line between them) while the other constraints are lower ranked (as can be seen from the order in which they occur in the tableau), does not follow from the interpretation of sentence (7). Rather, the tableau already presents the constraints in the ranking that we will develop in the course of this section. Obviously, cases such as (7) in which the optimal candidate does not violate any constraints at all do not allow us to determine the ranking within a set of constraints. In order to decide the ranking, we need to look at cases in which there is a conflict between constraints. Consider sentence (9) for example, where the optimal interpretation turns out to be the object-initial interpretation, which is illustrated in the tableau in (10):

(9) Den Zaun habe ich zerbrochen.

[the fence $]_{\mathrm{ACC}}$ have $\mathrm{I}_{\mathrm{NOM}}$ broken

"I broke the fence."

(10) Optimal interpretation of sentence (9)

\begin{tabular}{|r|c|c|c|c|c|}
\hline Den Zaun habe ich zerbrochen & CASE & AGREEMENT & SELECTION & PRECEDENCE & PROMINENCE \\
\hline SI & $*$ & $*$ & $*$ & & $*$ \\
\hline OI & & & & $*$ & \\
\hline
\end{tabular}


From the constraint violation pattern of the two candidates and the fact that the object-initial reading is the winner of the competition, we can deduce the following partial ranking: at least one of the constraints CASE, AGREEMENT, SELECTION, or PROMINENCE outranks PRECEDENCE. When we consider the interpretation of sentence (11) next, and the tableau in (12), we conclude that CASE by itself outranks PRECEDENCE, also when the other constraints are (vacuously) satisfied or violated (AGREEMENT because both arguments are third person singular, SELECTION and PROMINENCE because both arguments are equally prominent/ animate).

Den Lehrer hat [der Junge] geschlagen.
[the teacher $]_{\mathrm{ACC}}$ has $[\text { the boy }]_{\mathrm{NOM}}$ hit
"The boy hit the teacher."

(12) Optimal interpretation of sentence (11)

\begin{tabular}{|rrr|r|r|r|r|c|}
\hline $\begin{array}{l}\text { Den Lehrer hat der Junge } \\
\text { geschlagen. }\end{array}$ & CASE & AGREEMENT & SELECTION & PRECEDENCE & PROMINENCE \\
\hline & SI & $*$ & & & & $*$ \\
\hline & OI & & & & $*$ & $*$ \\
\hline
\end{tabular}

In the next example then, it becomes clear that in the absence of unambiguous case-marking, AGREEMENT by itself outranks PRECEDENCE too:

Die Lehrerinnen

[the teachers] $]_{\mathrm{NOM} / \mathrm{ACC}}$

"Bernhard hit the teachers." hat Bernhard

has Bernhard $_{\mathrm{NOM} / \mathrm{ACC}}$ hit

(14) Optimal interpretation of (13)

\begin{tabular}{|rr|c|c|c|c|c|}
\hline $\begin{array}{l}\text { Die Lehrerinnen hat Bernhard } \\
\text { geschlagen. }\end{array}$ & CASE & AGREEMENT & SELECTION & PRECEDENCE & PROMINENCE \\
\hline & SI & & $*$ & & & $*$ \\
\hline & OI & & & & $*$ & $*$ \\
\hline
\end{tabular}

Subsequently, in (15)-(16) the constraint SELECTION (this could also be PROMINENCE, but see the discussion later) is shown to outrank PRECEDENCE. 
(15)

Die Jacke hat Bernhard gesehen.

[the coat $]_{\text {NOM/ACC }}$ has Bernhard NOM/ACC $_{\text {seen }}$

"Bernhard saw the coat."

(16) Optimal interpretation of (15)

\begin{tabular}{|r|c|c|c|c|c|}
\hline Die Jacke hat Bernhard gesehen. & CASE & AGREEMENT & SELECTION & PRECEDENCE & PROMINENCE \\
\hline SI & & & $*$ & & $*$ \\
\hline OI & & & & $*$ & \\
\hline
\end{tabular}

Furthermore, from (17)-(18) we may deduce that CASE outranks SELECTION and PROMINENCE:

Der Zaun hat Bernhard zerbrochen.

[the fence $]_{\mathrm{NOM}}$ has Bernhard NOM/ACC $_{\text {broken }}$

"The fence broke Bernhard."

(18) Optimal interpretation of (17)

\begin{tabular}{|r|c|c|c|c|c|}
\hline Der Zaun hat Bernhard zerbrochen. & CASE & AGREEMENT & SELECTION & PRECEDENCE & PROMINENCE \\
\hline SI & & & $*$ & & $*$ \\
\hline OI & $*$ & & & $*$ & \\
\hline
\end{tabular}

That SELECTION outranks PRECEDENCE as well as PROMINENCE is deduced from the objectinitial interpretation obtained for sentence (19), as shown in the tableau in (20).
Bernhard
hat die Vorstellung
deprimiert.
Bernhard $_{\text {NOM/ACC }}$
has [the performance] $]_{\text {NOM/ACC }}$
depressed
"The performance depressed Bernhard." 
(20) Optimal interpretation of (19)

\begin{tabular}{|rr|c|c|c|c|c|}
\hline $\begin{array}{l}\text { Bernhard hat die Vorstellung } \\
\text { deprimiert. }\end{array}$ & CASE & AGREEMENT & SELECTION & PRECEDENCE & PROMINENCE \\
\hline SI & & & $*$ & & \\
\hline & & & & $*$ & $*$ \\
\hline
\end{tabular}

Finally, we can show that PRECEDENCE outranks PROMINENCE in a context where SELECTION is not involved. That is, the verb streifen 'brush' does not select for an animate subject nor for an animate object and the optimal reading we get for the ambiguous sentence in (21) is the subject-initial reading, which satisfies PRECEDENCE yet violates PROMINENCE.

(21)

$\begin{array}{lll}\text { Die Pflanze } & \text { streifte } & \text { Bernhard. } \\ \text { [The plant }]_{\text {NOM/ACC }} & \text { brushed } & \text { Bernhard }_{\text {NOM/ACC }}\end{array}$

"The plant brushed Bernhard."

(22) Optimal interpretation of (21)

\begin{tabular}{|r|c:c|c|c|c|}
\hline Die Pflanze streifte Bernhard. & CASE & AGREEMENT & SELECTION & PRECEDENCE & PROMINENCE \\
\hline SI & & & & & $*$ \\
\hline OI & & & & $*$ & \\
\hline
\end{tabular}

On the basis of the above sentences and their optimal (i.e., preferred) interpretations, we can establish the following ranking of our five DISTINGUISHABILITY constraints:

(23) \{ CASE, AGREEMENT $\}>>$ SELECTION $>>$ PRECEDENCE $>>$ PROMINENCE

We have not been able to determine the ranking between AGREEMENT and CASE, yet both constraints are stronger than the others and both give rise to ungrammatical sentences when violated. However, in this paper we are not interested in grammaticality per se, but in how the constraints and the conflicts among them help the hearer to arrive at the optimal interpretation of a given sentence (input).

Consider sentence (24) as a final example of this optimization process of interpretation.
Die Professorin
hat die Studentin
geschlagen.
[the professor $]_{\mathrm{NOM} / \mathrm{ACC}}$
has [the student $]_{\mathrm{NOM} / \mathrm{ACC}}$ hit
"The professor hit the student." 
In sentence (24) CASE cannot distinguish between the two noun phrases as they are both ambiguous between nominative and accusative case. Neither can PROMINENCE, SELECTION or AGREEMENT make the distinction. In other words, in this sentence only PRECEDENCE can be used to determine which argument is the subject and which one is the object. This constraint favours the reading such that the subject precedes the object and this is indeed the reading we get, at least when no additional contextual or intonational information to the contrary interferes. The following tableau illustrates that the object-initial reading becomes suboptimal on the basis of one constraint violation only.

(25) Optimal interpretation of sentence (24)

\begin{tabular}{|r|c|c|c|c|c|}
\hline $\begin{array}{l}\text { Die Professorin hat die Studentin } \\
\text { geschlagen. }\end{array}$ & CASE & AGREEMENT & SELECTION & PRECEDENCE & PROMINENCE \\
\hline OI & & & & $*$ & \\
\hline SI & & & & & \\
\hline
\end{tabular}

The phenomenon in which only word order determines the optimal interpretation is known as word order freezing in the literature (cf. Lee 2003, Zeevat, to appear). In this example, when two arguments of a transitive relation cannot be distinguished on the basis of case, agreement, animacy, the selection criteria of the verb or our world knowledge, only the canonical word order with its concomitant (subject precedes object) reading is available. Zeevat illustrates the phenomenon of freezing with Jakobson's (1984) observation that the Russian sentence Mat' ljubit doč' 'The mother loves the daughter' only allows a subject initial reading because mat' and $d o c ̌$ ' do not have different forms in the nominative and accusative.

\section{A model of incremental optimization of interpretation}

The theoretical perspective that we have so far taken and will continue to take in the remainder of this paper is that of Optimality Theory (cf. Prince and Smolensky 1997, 2004). The basic assumption of this type of linguistic theory is that the connectionist wellformedness measure called Harmony can be used to model linguistic well-formedness. The goal of Harmonic Grammar, as well as of its successor Optimality Theory (OT), is to provide a framework in which linguistic regularities are expressed by the use of violable rules, rather than hard rules. Within this perspective, constraints are naturally conceived of as violable, and 
potentially conflicting. A constraint is never violated without any reason, however, but only in order to satisfy another, stronger constraint. The fact that the conditions are soft has farreaching consequences: if all possible output candidates violate (or if all satisfy) a certain constraint, then this constraint is not relevant anymore for the determination of the optimal output.

This basic principle must have its effects on on-line comprehension. We assume that when a sentence (a form) is being processed, i.e., interpreted, the optimal interpretation of this form is being built up incrementally. Hence, we assume the process of optimization itself to be incremental. We are not the first to explore the use of OT constraints to explain sentence processing (cf. Gibson and Broihier 1998, Fanselow et al. 1999, Stevenson and Smolensky 2005). However, as far as we know we are the first who explore OT semantics rather than OT syntax to deal with processing. A subsequent account along these lines is offered by Hoeks and Hendriks (2005). We think that Optimality Theoretic semantics (cf. Hendriks and De Hoop 2001) gives a straightforward tool for analysing processing. Hendriks and De Hoop (2001) take as a point of departure free generation of interpretations in combination with the parallel evaluation of violable constraints. The integration of pragmatic, semantic, and syntactic information in a system of ranked constraints is proposed to correctly derive the optimal interpretations for inputs that consist of utterances, i.e., forms. So, in OT semantics, the direction of optimization is from form to meaning, it is optimization from the hearer's point of view. To use this approach for our purpose of analysing experimental results of processing requires an incremental approach to optimization. That is, the process of optimization of interpretation proceeds while the information comes in word by word, or constituent by constituent (for a similar approach to the role of animacy in transitive relations, see Lamers \& de Hoop, 2005).

How does this work? We will illustrate the idea with help of two examples, first the incremental optimization of sentence (7), repeated below for convenience.

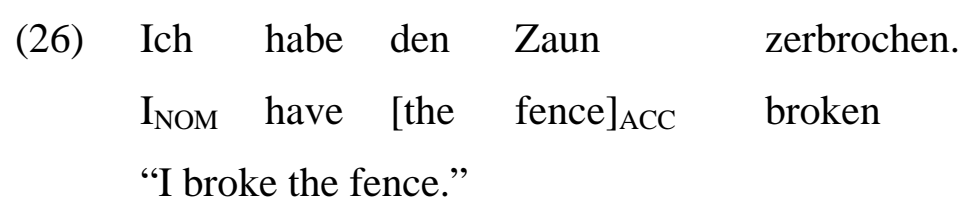

As we have argued above, the optimal interpretation of sentence (26) is the subject-initial interpretation. But how does this interpretation come about in the course of processing the sentence? We assume that hearers start to optimize the interpretation of an incoming sentence 
right away. When the first noun phrase of (26) comes in, the optimal interpretation is the subject-initial interpretation as that one does not violate any of the relevant constraints, while the object-initial interpretation would immediately violate PRECEDENCE as well as CASE. This is shown in the following tableau:

(27) Incremental optimization of sentence (26): Stage I

\begin{tabular}{|r|c:c|c|c|c|}
\hline Ich... & CASE & AGREEMENT & SELECTION & PRECEDENCE & PROMINENCE \\
\hline \multirow{*}{*}{ SI } & & & & & \\
\hline OI & $*$ & & & $*$ & \\
\hline
\end{tabular}

At the next incoming word, habe 'have', the subject-initial interpretation would be maintained while at the third constituent, den Zaun 'the fence', the object-initial interpretation would moreover violate AGREEMENT and PROMINENCE .

(28) Incremental optimization of sentence (26): Stage III

\begin{tabular}{|r|c|c|c|c|c|}
\hline Ich habe den Zaun... & CASE & AGREEMENT & SELECTION & PRECEDENCE & PROMINENCE \\
\hline SI & & & & & \\
\hline OI & $*$ & $*$ & & $*$ & $*$ \\
\hline
\end{tabular}

Finally, at the last word, the verb, the object-initial interpretation would cause a violation of SELECTION as well.

(29) Incremental optimization of sentence (26): Stage IV

\begin{tabular}{|r|c:c|c|c|c|}
\hline Ich habe den Zaun zerbrochen. & CASE & AGREEMENT & SELECTION & PRECEDENCE & PROMINENCE \\
\hline SI & & & & & \\
\hline OI & $*$ & $*$ & $*$ & $*$ & $*$ \\
\hline
\end{tabular}

Clearly, then, the subject-initial interpretation is maintained as the optimal interpretation from the first word until the last one, whereas the Harmony value of the object-initial interpretation more and more decreases in time.

Not all sentences maintain the same optimal interpretation in the course of processing. We also find examples that show a 'jump' from one optimal interpretation to another at a certain stage. For example, reconsider sentence (15), repeated below as (30), and note that in 
this case we begin with a subject-initial reading as the optimal interpretation but we end up with the object-initial reading as the optimal one.

\begin{tabular}{|c|c|c|c|}
\hline Die Jacke & hat & Bernhard & gesehen. \\
\hline$[\text { the coat }]_{\mathrm{NOM} / \mathrm{ACC}}$ & has & Bernhard $_{\mathrm{NOM} / \mathrm{ACC}}$ & seen \\
\hline
\end{tabular}

How does this interpretation arise incrementally? When the first noun phrase is encountered, we interpret it as the subject despite the violation of PROMINENCE that this interpretation gives rise to, since the other candidate reading, the object-initial one, would violate the higher ranked constraint PRECEDENCE. Crucially, the case morphology is ambiguous between nominative and accusative marking.

(31) Incremental optimization of sentence (30): Stage I

\begin{tabular}{|r|c:c|c|c|c|}
\hline Die Jacke... & CASE & AGREEMENT & SELECTION & PRECEDENCE & PROMINENCE \\
\hline SI & & & & & $*$ \\
\hline OI & & & & $*$ & \\
\hline
\end{tabular}

Because the second noun phrase is ambiguous in case-marking as well, and moreover, both noun phrases are third person singular, the subject-initial reading is actually maintained as the optimal interpretation until the final word, the verb. Then, SELECTION comes into play, and the result is that the object-initial interpretation becomes the optimal one. This is illustrated in the tableau below:

(32) Incremental optimization of sentence (30): Stages III and IV

\begin{tabular}{|r|l|c|c|c|c|c|}
\hline $\begin{array}{l}\text { Die Jacke hat } \\
\text { Bernhard... } \\
<\mathrm{III}>\end{array}$ & $\begin{array}{l}\text {.. gesehen. } \\
<\mathrm{IV}>\end{array}$ & CASE & AGREEMENT & SELECTION & PRECEDENCE & PROMINENCE \\
\hline OI & SI & & & $*$ & $*$ & $*$ \\
\hline OI & & & & $*$ & \\
\hline
\end{tabular}

So, while at stage III the subject-initial reading is still the optimal one, at stage IV we observe a crucial change. Due to the selection properties of the verb gesehen 'seen', the best interpretation is now the object-initial one, since only that one can satisfy SELECTION (to see 
requires an animate subject), at the cost of violating PRECEDENCE though. In the tableau above the constraint violation pattern corresponds to the fourth stage only. In the earlier stage (stage III), SELECTION had not been violated yet because the verb had not been processed yet. We say that the hearer 'jumps' from the subject-initial reading of stage III to the object-initial reading of stage $\mathrm{IV}$.

Obviously, we have also seen examples where the object-initial reading is the optimal one right from the beginning. This is for example the case with respect to sentence (1) above,

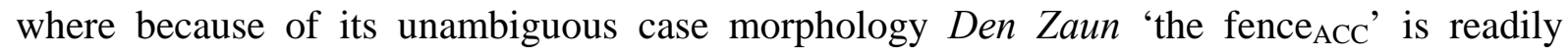
interpreted as the object despite the fact that it is sentence-initial.

Finally, it goes without saying that the DistinguishaBILITY subconstraints we have discussed above are not the only constraints that play a part in determining the optimal interpretation of transitive sentences. And satisfaction of DisTINGUISHABILITY may itself be in conflict with other violable constraints, such as, from the perspective of the speaker, a constraint that penalizes marking of an otherwise unmarked argument (cf. Malchukov, this volume).

\section{Processing effects related to distinguishability}

Having proposed our new model of incremental optimization of interpretation, we can use it to evaluate sentences used in on-line studies in which DisTingUISHABILITY was manipulated. We will apply our model to four studies in which event related brain potentials were measured, two studies by Lamers (2001), one by Frisch and Schlesewsky (2001), and one by Schlesewsky and Frisch (submitted). The latter two studies are discussed in Schlesewsky and Bornkessel (2004).

Event related brain potentials (ERPs) are small changes in spontaneous electrical activity of the brain that occur in response to certain stimuli. They can be recorded continuously and noninvasively by means of electrodes attached to the scalp. Because of the high temporal resolution of the ERP signal with its various dimensions, ERPs have been proven to be particularly useful to investigate the time-course of brain activity related to language processing without introducing an extra unrelated task. One well-known effect (“component”) is the so-called $N 400$, which is an enhanced negative effect with a peak around $400 \mathrm{~ms}$ post-stimulus largest over central and right posterior electrode sites that is found for difficulties related to semantic/pragmatic integration processes. In relation to syntactic difficulties a late positivity has been reported with an onset of approximately $500 \mathrm{~ms}$ with a 
maximum at $600 \mathrm{~ms}$ after onset of the critical word at centroparietal sites (usually referred to as the P600). In this section, we will discuss some relevant ERP-effects in terms of incremental distinguishability between subjects and objects when interpreting transitive sentences. We evaluate the information constituent by constituent against the ranked constraints CASE $>>$ SELECTION $>>$ PRECEDENCE $>>$ PROMINENCE (AGREEMENT will not play a role in the remainder of this article) under the assumption that Dutch has the same ranking as German.

Lamers (2001) in two ERP studies investigated Dutch sentences such as given in (33), (34) and (35):

(33) De oude vrouw in the straat verzorgde hem ... the old woman in the street took-care-of him ... "The old woman in the street took care of him ..."

(34) Het oude park in the straat verzorgde hij ... the old park in the street took-care-of he ... "He took care of the old park in the street ..."

(35) De oude vrouw in the straat verzorgde hij ... the old woman in the street took-care-of he ... "He took care of the old woman in the street ..."

When people start to interpret sentences (33)-(35), they interpret the initial noun phrase as the subject (in accordance with PRECEDENCE). However, when the verb is encountered, the inanimate initial noun phrase in (34) can no longer be interpreted as the subject because of the selectional restrictions of the verb (verzorgde 'took care of' requires an animate subject). The sentences in (33) and (35), on the other hand, maintain the subject-initial reading as the optimal interpretation until the second noun phrase. However, when the nominative casemarked pronoun is encountered in (35), CASE overrules PRECEDENCE. As a result, the objectinitial reading becomes the optimal interpretation for (35). Only sentence (33) can maintain the preferred subject-initial reading until the very end of the sentence.

At this point, let us have a look at the the tableau of sentence (33). The interpretations at the three stages of processing are given in the first three columns. The violation pattern of the constraints shown in the three rightmost columns of the tableau reflects the pattern of only 
the final - third - stage (in the first two stages, CASE is not violated by the object-initial reading yet, only PRECEDENCE is). The subject-initial reading is maintained throughout the three stages of interpretation. Only the three distinguishability constraints that are relevant for this example are given in the tableau.

(36) Incremental optimization of sentence (33): Stages I, II and III

\begin{tabular}{|l|l|l|l|l|l|}
\hline $\begin{array}{l}\text { De oude vrouw... } \\
\text { 'the old lady' }\end{array}$ & $\begin{array}{l}\text { verzorgde... } \\
\text { 'took care of' } \\
<\mathrm{I}>\end{array}$ & $\begin{array}{l}\text { hem... } \\
\text { 'him' } \\
<\mathrm{II}>\end{array}$ & CASE & SELECTION & PrECEDENCE \\
\hline $\mathrm{SI}$ & $\mathrm{III}>$ & & & \\
\hline $\mathrm{OI}$ & $\mathrm{OI}$ & $\mathrm{OI}$ & $*$ & & \\
\hline
\end{tabular}

Subsequently, consider the tableau in (37) below that gives the incremental interpretation of sentence (34). Up to the verb SELECTION does not play a role in the parsing process but at the verb, it becomes clear that the subject has to be animate. Hence, the optimal interpretation of the initial inanimate NP changes from subject to object. The optimal (object-initial) interpretation clearly violates PRECEDENCE but the stronger constraint SELECTION is satisfied. The incremental interpretation of sentence (34) involves a 'jump' from the subject-initial to the object-initial interpretation. It is at this point in the sentence (i.e., at the verb) that Lamers (2001) found significant ERP effects (early and late positivities) for sentence (34) compared to (33).

(37) Incremental optimization of sentence (34): Stages I and II

\begin{tabular}{|r|l|l|l|l|}
\hline $\begin{array}{l}\text { Het oude park... } \\
\text { 'the old park' } \\
<\mathrm{I}>\end{array}$ & $\begin{array}{l}\text { verzorgde... } \\
\text { 'took care of' } \\
<\mathrm{II}>\end{array}$ & CASE & SELECTION & PRECEDENCE \\
\hline $\mathrm{SI}$ & $\mathrm{SI}$ & & $*$ & \\
\hline $\mathrm{OI}$ & $\mathrm{OI}$ & & & $*$ \\
\hline
\end{tabular}

Finally, the tableau in (38) presents a schematic overview of the constraint violations pattern of the crucial words of sentence (35). 
(38) Incremental optimization of sentence (35): Stages I, II and III

\begin{tabular}{|l|l|l|l|l|l|}
\hline $\begin{array}{l}\text { De oude vrouw... } \\
\text { 'the old lady' }\end{array}$ & $\begin{array}{l}\text { verzorgde... } \\
\text { 'took care of' } \\
<\mathrm{II}>\end{array}$ & $\begin{array}{l}\text { hij... } \\
\text { 'he' } \\
<\mathrm{III}>\end{array}$ & CASE & SELECTION & PRECEDENCE \\
\hline $\mathrm{SI}$ & $\mathrm{SI}$ & $\mathrm{SI}$ & $*$ & & \\
\hline $\mathrm{OI}$ & $\mathrm{OI}$ & $\mathrm{OI}$ & & & $*$ \\
\hline
\end{tabular}

Let us now compare the pattern of constraint violations found at the nominative case-marked pronoun to the pattern observed at the verb of the sentence starting with the inanimate NP. At the nominative case-marked pronoun the object-initial interpretation overrules the subjectinitial interpretation, which was optimal until that point. At that time (i.e., at the second noun phrase), we get a similar 'jump' from one interpretation to the other, as we have seen with respect to the incremental interpretation of sentence (34). Again, the object-initial interpretation violates PRECEDENCE but the stronger constraint, CASE, is satisfied. In other words, the resulting pattern is basically the same pattern as the one created at the verb in the inanimate condition (34). And since Lamers found similar ERP effects, i.e., early and late positivities at the case-marked pronoun in (35) as well as at the verb in (34), we conclude that the ERP effects indeed reflect the similar constraint violation patterns in our model. Note that until the pronoun is encountered PROMINENCE does not play a role because only one argument is present. The nominative case-marked pronoun is the second argument and then it becomes clear that both arguments are animate. However, we assume that PROMINENCE is not violated since in discourse/animacy hierarchies pronouns are considered to be higher in prominence than noun phrases (cf. Yamamoto 1999).

An interesting question is whether structures in which different (types of) constraints are violated give rise to (qualitatively) different effects (in terms of ERP measures). We will show below that existing evidence from German suggests that a violation of PROMINENCE is associated with an N400. First, consider the following (ungrammatical) indirect questions that were used in an experiment by Frisch \& Schlesewsky (2001):

*... welcher Bischof

... [which bishop $]_{\mathrm{NOM}}$
*... welcher Bischof

... [which bishop $]_{\mathrm{NOM}}$ der Zweig streifte.

[the twig] $]_{\text {NOM }}$ brushed

der Priester

begleitete.

[the priest $]_{\mathrm{NOM}}$ accompanied 
Both sentences above are rendered ungrammatical at the position of the second noun phrase because sentences with two nominative arguments are ill-formed in German. In other words, in both sentences CASE is vacuously violated, albeit unexpectedly. In terms of DisTINGUISHABILITY, the second nominative-marked argument induces a problem, since the case marking of each argument suggests that this argument is the subject. However, the sentences differ with respect to ProminenCE. The latter constraint can still be satisfied in (39) where the two arguments differ in terms of animacy, but not in (40) where there is no difference in animacy between the two noun phrases. Hence, in addition to the violation of CASE in both sentences, sentence (40) is 'worse' or more difficult to process since Prominence is violated as well. And indeed, Frisch \& Schlesewsky (2001) observed a biphasic ERP pattern of an N400 and a P600 component for the ungrammatical sentence (40), while only a P600 for the equally ungrammatical (39), in comparison to minimally differing, grammatical control conditions.

Thus, the N400 in the above example apparently reflects a violation of PROMINENCE and therefore in combination with the lack of a morphological case distinction a reduced fulfilment of DistinguishabiLiTy. Although the sentences in (39) and (40) are equally ungrammatical because both noun phrases bear nominative case, sentence (40) gives rise to an extra processing problem because of the violation of PROMINENCE. In a tableau:

(41) Incremental optimization of sentence (39): Stages I and II

\begin{tabular}{|c|c|c|c|c|}
\hline $\begin{array}{l}\text { Welcher Bischof... } \\
\text { 'which bishop' } \\
<\text { I }>\end{array}$ & $\begin{array}{l}\text { der Zweig... } \\
\text { 'the twig' } \\
<\text { II }>\end{array}$ & CASE & PRECEDENCE & PROMINENCE \\
\hline SI & $\mathrm{SI}$ & $*$ & & \\
\hline OI & OI & $*$ & * & $* *$ \\
\hline
\end{tabular}

We assume that the object initial reading of sentence (39) gives in fact a double violation of Prominence because not only does the subject fail to outrank the object in animacy, but moroever, the object outranks the subject. We need to assume this 'double violation' (the object outranks the subject in animacy) also in order to be able to explain the findings of the other ERP study, that we discuss at the end of this section. Now compare the tableau in (41) to the tableau in (42) which represents the incremental interpretation of sentence (40): 
(42) Incremental optimization of sentence (40): Stages I and II

\begin{tabular}{|l|l|l|l|l|}
\hline $\begin{array}{l}\text { Welcher Bischof... } \\
\text { 'which bishop' } \\
<\mathrm{I}>\end{array}$ & $\begin{array}{l}\text { der Priester... } \\
\text { 'the priest' } \\
<\mathrm{II}>\end{array}$ & CASE & PRECEDENCE & PROMINENCE \\
\hline $\mathrm{SI}$ & $\mathrm{OI}$ & $*$ & $*$ & $*$ \\
\hline $\mathrm{OI}$ & & $*$ \\
\hline
\end{tabular}

The difference between the constraint violation patterns of sentence (39) and (40) is clearly a difference with respect to the distinguishability condition PROMINENCE and that difference gives rise to an N400 at the second noun phrase in sentence (40). As we can see from a comparison of the constraint violation patterns of the optimal subject-initial interpretation, the N400 in stage II of the processing of (40) in comparison to the sentence in (39) corresponds to a violation of PROMinence. In principle, PreCEDENCE would still favour the subject-initial reading. However, as Vogel (2004) pointed out, the effect of PRECEDENCE is much weaker, or even seems to disappear, when one noun phrase is a wh-phrase, while the other is not. This corresponds to the fact that a $w h$-phrase preferably occupies the sentence-initial position for reasons of question-marking and question-scope, so we may expect a conflict between PRECEDENCE and a constraint of wh-movement here (cf. Ackema and Neeleman 1998). Whatever the exact role of PRECEDENCE is in (39) and (40), it cannot make a difference between the sentences, while on the other hand PROMINENCE clearly distinguishes between the two.

We would like to argue that in German the absence of accusative case-marking is worse in sentence (40) than in (39) because in (40) both noun phrases are animate, although in fact both (39) and (40) are ungrammatical due to the lack of accusative case. In other languages, we find a similar effect of animacy. In Malayalam, for instance, accusative casemarking is only present when the subject and the object are both animate (as in (44)). However, if the subject outranks the object in animacy (as in (43)), distinguishability is saved and the accusative case-marking is omitted (Asher and Kumari, 1997).

(43) naan teenjnja vaanjnji.

I coconut bought

"I bought a coconut."

(44) avan oru pasjuvin-e vanjnji. he a cow-ACC bought "He bought a cow." 
Another trigger for an N400 effect arises at the position of an inanimate second argument in indirect questions, in comparison to an animate nominative argument in the same position (Schlesewsky \& Bornkessel, 2004). Schlesewsky and Bornkessel (2004) discuss some results from Schlesewsky and Frisch (submitted) indicating that the processing of an initial animate accusative marked $w h$-argument gives rise to the prediction of an animate, nominative marked argument. If this prediction is not borne out and an inanimate nominative argument is encountered instead, an N400 is elicited. Thus, sentence (46) shows an N400 effect at the second noun phrase compared to sentence (45):

... welchen Bischof

... [which bishop $]_{\text {ACC }}$ der Priester

[the priest $]_{\mathrm{NOM}}$ der Zweig streifte.

... [which bishop $]_{\mathrm{ACC}}$ [the twig] $]_{\mathrm{NOM}}$ brushed begleitete.

accompanied

We claim that the N400 effect again reflects a (worse) violation of PROMINENCE. We assume that while a constraint such as PRECEDENCE can only be satisfied (when the subject precedes the object) or violated (when the object precedes the subject), a constraint like PROMINENCE can be violated to different degrees. One violation (indicated with one asterisk) is when the subject does not outrank the object in prominence (e.g., the subject and object are either both animate, or they are both inanimate). A worse violation (indicated with two asterisks) is when the object in fact outranks the subject, which is the case in sentence (46). Consider the corresponding tableaux:

(47) Incremental optimization of sentence (45): Stages I and II

\begin{tabular}{|l|l|l|l|l|}
\hline $\begin{array}{l}\text { Welchen Bischof... } \\
\text { 'which bishop' } \\
<\mathrm{I}>\end{array}$ & $\begin{array}{l}\text { der Priester... } \\
\text { 'the priest' } \\
<\mathrm{II}>\end{array}$ & CASE & PRECEDENCE & PROMINENCE \\
\hline $\mathrm{SI}$ & $\mathrm{SI}$ & $*$ & & $*$ \\
\hline $\mathrm{OI}$ & & & $*$ & $*$ \\
\hline
\end{tabular}


(48) Incremental optimization of sentence (46): Stages I and II

\begin{tabular}{|l|l|l|l|l|}
\hline $\begin{array}{l}\text { Welchen Bischof... } \\
\text { 'which bishop' } \\
<\mathrm{I}>\end{array}$ & $\begin{array}{l}\text { der Zweig... } \\
\text { 'the twig' } \\
<\mathrm{II}>\end{array}$ & CASE & PRECEDENCE & PROMINENCE \\
\hline $\mathrm{SI}$ & $\mathrm{SI}$ & $*$ & & \\
\hline $\mathrm{OI}$ & $\mathrm{OI}$ & & $*$ & $* *$ \\
\hline
\end{tabular}

As we can see from a comparison of the constraint violation patterns, the N400 for sentence (46) compared to sentence (45) corresponds to a worse violation of PROMINENCE under the optimal (here the object-initial) interpretation. The object-initial interpretation is optimal in both sentences because the subject-initial interpretation would induce a violation of the highest ranked constraint CASE. The difference between (45) and (46) is that in (46) the object in fact outranks the subject in terms of animacy and thus, we get a worse violation of PROMINENCE than when there is no difference in animacy between the subject and the object, as in (45). Again similar ERP effects from two studies (Frisch and Schlesewsky 2001, Schlesewsky and Frisch, submitted) appear to reflect similar constraint violation patterns in our incremental optimization of interpretation model.

\section{Conclusion}

When a hearer or reader interprets a transitive sentence, the two arguments of the transitive verb, to wit the subject and the object, should be distinguishable. We claim that such disinguishability is guaranteed by violable DisTINGUISHABILITY-subconstraints, that distinguish between transitive subjects and objects on the basis of (i) case morphology, (ii) agreement, (iii) selectional criteria of the verb, (iv) word order, and (v) prominence, in particular animacy. In this paper we have shown how the application of DisTINGUISHABILITY may be examined from an incremental optimization perspective. We propose a new model of incremental optimization of interpretation and we argue that this model can straightforwardly account for the findings of several on-line studies in which DistinguishaBILITY was manipulated. We have shown that the violation patterns that come about by checking the constraints incrementally (i.e. on each word or constituent) correspond to the differences in waveforms found in the relevant ERP studies. 


\section{References}

Ackema, P. \& A. Neeleman (1998), Optimal Questions. Natural Language and Linguistic Theory, 16, 443-490.

Aissen, J. (2003), Differential Object Marking: Iconicity vs. Economy. Natural Language and Linguistic Theory, 21, 435-483.

Asher, R. \& T. Kumari (1997), Malayalam. Routledge, London/New York.

Bobaljik, J. (1993), Nominally Absolutive is not Absolutely Nominative. Proceedings of the Eleventh West Coast Conference on Formal Linguistics, University of California, CSLI, Stanford.

Bornkessel, I. (2002), The Argument Dependency Model: A Neurocognitive Approach to Incremental Interpretation. Leipzig: MPI-Series in Cognitive Neuroscience, 28.

Comrie, B. (1989), Language Universals and Linguistic Typology. University of Chicago Press, Chicago.

Fanselow, G., M. Schlesewsky, D. Cavar, \& R. Kliegl (1999), Optimal parsing: Syntactic parsing preferences and Optimality Theory. Unpublished manuscript, University of Potsdam. [ROA, 367-1299]

Frisch, S., \& M. Schlesewsky (2001), The N400 indicates problems of thematic hierarchising. NeuroReport, 12, 3391 - 3394.

Gibson, E. (1998), Linguistic complexity: Locality of syntactic dependencies. Cognition, 68, $1-76$.

Gibson, E., \& K. Broihier (1998), Optimality theory and human sentence processing. In: P. Barbosa, D. Fox, P. Hagstrom, M. McGinnis, \& D. Pesetsky (eds.), Is the best good enough? Optimality and competition in syntax. MIT-Press, Cambridge.

Hendriks, P. \& H. de Hoop (2001), Optimality Theoretic Semantics, in Linguistics and Philosophy, 24, 1-32.

Hoeks, J.C.J. \& P. Hendriks (2005), Optimality Theory and human sentence processing: the case of coordination. In: B.G. Bara, L. Barsalou, \& M. Bucciarelli (eds.), Proceedings of the Twenty-Seventh Annual Conference of the Cognitive Science Society. Erlbaum, Mahwah, NJ, pp. 959-964.

Jakobson (1984), Morphological observations on Slavic declension (the structure of Russian case forms). In L.R. Waugh and M. Halle (eds), Roman Jakobson. Russian and Slavic grammar: Studies 1931-1981. Mouton de Gruyter, Berlin.

Lamers, M.J.A. (2001), Sentence processing: using syntactic, semantic, and thematic information. PhD dissertation University of Groningen. 
Lamers, M.J.A. and H. de Hoop (2005), Animacy information in human sentence processing: an incremental optimization of interpretation approach. In: H. Christiansen,, P.R. Skadhauge, \& J. Villadsen (eds.), Constraint Solving and Language Processing (Lecture Notes in Artificial Intelligence 3438). Springer- Verlag, Berlin/Heidelberg, pp. 158-171.

Lee, H. (2003), Parallel Optimization in Case Systems. In M. Butt and T. King (eds), Nominals: Inside and Out. CSLI, Stanford.

Malchukov, A. (this volume), Transitivity parameters and transitivity alternations: Constraining co-variation.

Næss, A. (2004), What markedness marks: The markedness problem with direct objects. Lingua, 114, 1186-1212.

Prince, A. and Smolensky, P. (1997), Optimality: From neural networks to universal grammar. Science, 275, 1604-1610.

Prince, A. and Smolensky, P. (2004), Optimality Theory: Constraint Interaction in Generative Grammar. Blackwell, Oxford.

Schlesewsky, M., and I. Bornkessel (2004), On incremental interpretation: Degrees of meaning accessed during sentence comprehension. Lingua, 114, 1213-1234.

Schlesewsky, M. \& S. Frisch (submitted), Why the "subject preference" is more than a "subject" preference: the role of non-syntactic features in parsing expectations. Manuscript University of Marburg and University of Potsdam.

Stevenson, S., \& P. Smolensky (2005), Optimality in sentence processing. In: P. Smolensky \& G. Legendre (eds.), The Harmonic Mind. MIT Press, Cambridge.

Swart, P. de (2003), The Case Mirror, MA Thesis, University of Nijmegen.

Swart, P. de (this volume), Case Markedness.

Vogel, R. (2004), Correspondence in OT Syntax and Minimal Link Effects. In: Stepanov, G.

Fanselow, \& R. Vogel (eds.), Minimality Effects in Syntax. De Gruyter, Berlin.

Yamamoto, M. (1999), Animacy and Reference: A Cognitive Approach to Corpus Linguistics. John Benjamins, Amsterdam/Philadelphia.

Zeevat, H. (to appear), Freezing and Marking. To appear in: Linguistics (2006).

Zwarts, F. (1981), Negatief polaire uitdrukkingen 1. GLOT, 4, 35-132. 